\title{
CUIDADOS E COMPLICAÇÕES PÓS-OPERATÓRIAS
}

\author{
CARE AND COMPLICATIONS POST-SURGICAL
}

Luís Donizeti da Silva Stracieri

Docente. Divisão de Cirurgia de Urgência do Departamento de Cirurgia e Anatomia - HCFMRP-USP

CorResPondÊncia: Divisão de Cirurgia de Urgência do Departamento de Cirurgia e Anatomia da FMRP-USP.

Av. Bandeirantes, 3900, 14049-900 - Ribeirão Preto / SP. (email: luisstracieri@gmail.com.br 0

Stracieri LDS. Cuidados e complicações pós-operatórias. Medicina (Ribeirão Preto) 2008; 41 (4): 465-8.

RESUMO: O trabalho destaca os principais cuidados no período pós-operatório quanto às condições clínicas e recuperação anestésica. Apresenta os principais fatores que envolvem a dor, a infecção e as complicações respiratórias e cardiovasculares e outras complicações específicas.

Descritores: Período Pós-Operatório. Complicações Pós-Operatórias. Cuidados Pós-Operatórios.

\section{1- INTRODUÇÃO}

O paciente psicologicamente bem adaptado, cujos sistemas orgânicos principais funcionam segundo suas necessidades, com nutrição, balanços hidreletrolítico e ácido-básico normais, geralmente tolera uma intervenção cirúrgica.

As ordens médicas no pós-operatório seguem linhas gerais. Verificam-se rotineiramente: o estado de consciência, as condições de hidratação e balanço hídrico, o estado das condições de ventilação e oxigenação, das condições hemodinâmicas, observam-se o estado das cicatrizes cirúrgicas e o funcionamento de drenos, sondas e cateteres. Durante a recuperação anestésica é dedicado cuidado especial ao estado hemodinâmico e às condições ventilatórias. O reinício da movimentação deve ser precoce, contudo depende do tipo e da extensão da cirurgia. Recomenda-se a mudança de decúbito várias vezes ao dia no sentido de prevenir o acúmulo de secreções e a atelectasia pulmonar.

\section{1- Controle da dor pós-operatória}

A presença da dor no pós-operatório dificulta a mobilização ativa, restringe o esforço para a tosse produtiva, leva à hipoventilação e compromete o estado geral do paciente operado. Geralmente é mais intensa nas primeiras 24 a 36 horas, sendo que na maioria dos casos já se observa melhora nas primeiras 48 horas.

\section{2- Fatores que favorecem a infecção}

Nas primeiras 48 horas de pós-operatório podese observar elevação da temperatura até $38^{\circ} \mathrm{C}$ conseqüente à elevação do metabolismo e ao trauma cirúrgico. A atelectasia e a pneumonite são as causas mais freqüentes de febre nos três primeiros dias pós-operatórios; crise tireotóxica também pode associar-se precocemente com febre pós-operatória. Do terceiro ao sexto da cirurgia deve-se pensar em infecção de cateteres vasculares, infecção urinária ou incisional, peritonite localizada ou generalizada, além de tromboflebite de membros inferiores. Do sexto ao décimo dia surgem como complicações sépticas, causadoras de febre, os abscessos incisionais e as coleções purulentas.

Os fatores sistêmicos que favorecem o surgimento de infecção cirúrgica são: desnutrição, obesidade, presença de infecção concomitante em outro local do corpo, depressão da imunidade, uso de corticoesteróides e citotóxicos, diabete melito, hospitalização prolongada, doenças debilitantes e consumptivas como neoplasias. 


\section{3- Aparelho respiratório}

As complicações pulmonares são as mais comumente observadas no período pós-operatório. Pacientes com doença pulmonar obstrutiva crônica constituem grupo de especial vulnerabilidade devido ao fato de freqüentemente apresentarem aumento de volume da secreção brônquica, diminuição da atividade ciliar do epitélio e tendência a acúmulo de secreções.

\section{4- Atelectasia}

A atelectasia é a complicação pulmonar mais comum no pós-operatório. Surge habitualmente nas primeiras 48 horas, sua ocorrência deve ser suspeitada pela verificação de febre, taquipnéia e taquicardia neste período.

\section{5- Pneumonia}

A pneumonia é complicação mais freqüente das atelectasias persistentes ou da aspiração de secreções. O diagnóstico clínico de pneumonia é sugerido pelo encontro de calafrios, febre elevada, dor pleurítica e tosse com expectoração. Os dados do exame físico freqüientemente não se correlacionam bem com os achados radiológicos na fase inicial do processo; sendo assim, suspeitando-se da ocorrência da complicação, deve-se submeter o paciente a estudo radiológico do tórax.

\section{6- Embolia Pulmonar}

A embolia pulmonar é complicação mais freqüiente no pós-operatório de indivíduos imobilizados por longo período de tempo, nos idosos, nas cirurgias pélvicas e do colo do fêmur, nos cardiopatas, nos obesos, em pacientes com história de acidentes tromboembólicos e naqueles apresentando insuficiência venosa periférica ou em uso de anovulatórios. O principal fator na fisiopatogenia é o estado de hipercoagulabilidade sangüínea no pós-operatório. Na maioria das vezes a embolia pulmonar ocorre sem prévia manifestação de sinais de trombose venosa. Apenas cerca de $10 \%$ dos casos de embolização venosa produzem infarto pulmonar com manifestações clínicas características.

\section{7- Aparelho Cardiovascular}

A causa mais comum de deterioração cardiocirculatória em pacientes cardiopatas submetidos a um procedimento cirúrgico de vulto é a hipovolemia. Devese avaliar com especial atenção as perdas hidreletrolíticas e sanguiíneas ocorridas durante o ato cirúrgico, assim como as necessidades e a qualidade da reposição pós-operatória. Em pacientes submetidos a cirurgias de grande porte a reincidência de infarto é tanto mais elevada quanto mais recente tenha sido o evento antecedente.

\section{2- COMPLICAÇÕES PÓS-OPERATÓRIAS}

O cirurgião é o médico que espera curar o paciente através de uma ferida. Após a remoção de um foco patológico, pode-se gerar uma doença pós-operatória de evolução imprevisível. Apesar da perícia técnica e da evolução da doença pós-operatória, todas as operações são perigosas. Nenhuma delas é isenta de complicações.

Toda complicação cirúrgica constitui um acontecimento marcante. A maioria dos cirurgiões nunca relembra os pacientes que terminam bem e jamais esquece os que evoluem sob o estigma de uma complicação. Nesta, há sensação de perda perante o operado e a de fracasso ao cirurgião.

Em relação ao fator tempo, as complicações são divididas em imediatas, mediatas ou tardias. São imediatas ou precoces as complicações que surgem nas primeiras 24 horas, mediatas até o sétimo dia e tardias as que acontecem depois da retirada de pontos e de alta hospitalar definitiva.

Quanto aos sistemas orgânicos básicos, passíveis de descompensação no período pós-operatório, as complicações surgem nos sistemas: respiratório, cardiovascular, urinário, digestório e hepatobiliar.

De maneira genérica as complicações cirúrgicas distribuem-se em grupos que, se não completos, pretendem ser didáticos, no entendimento do raciocínio clínico.

\section{1- Complicação Geral}

É aquela que pode acontecer a todo operado e em qualquer setor do organismo. Exemplo universal é representado pela hemorragia. Apresenta como fatores etiológicos mais exuberantes a ruptura de ligadura ou hemostasia deficiente. A repercussão clínica depende do tipo de sangramento, calibre do vaso e da quantidade de sangue perdido numa fração de tempo. Hipovolemia que coloca em risco a vida do operado necessita diagnóstico precoce e hemostasia definitiva por uma reoperação.

Além do choque hemorrágico, outras complicações gerais são representadas pela atelectasia pulmonar, insuficiência renal aguda e doença tromboembólica. 


\section{2- Complicação Especial}

É aquela que afeta um determinado grupo de pessoas portadoras de uma afecção clínica pré-existente.

\section{3- Complicações Específicas}

São aquelas inerentes ao órgão operado. As complicações de mastectomia não podem ser as mesmas de uma histerectomia. As complicações da colecistectomia são tanto precoces como tardias.

A freqüência de complicações cirúrgicas é proporcional à afecção clínica associada, tipo de anestesia, além do grau de injúria e os cuidados pós-operatórios.

Em cirurgia, a morbidade e a mortalidade tendem a diminuir. Pacientes desnutridos, anêmicos e imunodeprimidos apresentam evolução pós-operatória cercada pelo risco de complicações.

Abdômen agudo cirúrgico e trauma abdominal apresentam alta porcentagem de infecção cirúrgica, depois da laparotomia. Intervenções oncológicas em idosos são seguidas de elevada frequiência de complicações relacionadas à idade avançada, afecção clínica em sistema nobre e maior ferida operatória. A hipertensão arterial e o diabete melito acarretam as mais comuns, freqüentes e graves complicações.

A insuficiência renal aguda no pós-operatório está vinculada muito mais à hemorragia e à desidratação que à estrutura histológica e desempenho funcional glomerular.

A iatrogenia cirúrgica constitui-se em verdadeiro ninho de complicações. O acidente transoperatório não diagnosticado e não corrigido evolui para uma precoce e grave complicação. A responsabilidade do cirurgião em evitar uma complicação está vinculada à evolução técnica, mudança de conduta e grande agressão cirúrgica.

\section{4- Evolução Pós-Operatória}

Evolução normal é aquela que conduz, sem atropelos, todo operado do trauma operatório à cura. Evolução anormal é crivada de alterações orgânicas e distúrbios funcionais capazes de identificar uma complicação pós-operatória.

Em cirurgia abdominal, devemos dominar por completo o íleo funcional; é habitual e relaciona-se ao manuseio cirúrgico visceral e processo inflamatório intraperitoneal. Conviver com íleo funcional constitui uma rotina imprescindível, todas as vezes que se pretende seguir a evolução pós-operatória de um paciente.

Na evolução pós-operatória três problemas devem ser debelados:
1. Combate ao jejum prolongado por uma judiciosa reposição tanto hidroeletrolítica quanto calórica.

2. Combate à dor, elegendo mais um analgésico que um narcótico, este capaz de aumentar a incidência de complicações graves.

3. Combate à infecção através de antibioticoterapia.

\section{5- Problemas Diversos}

Problemas diversos são constituídos por sintomas ou sinais isolados que identificam ou representam o início de uma síndrome clínica pós-operatória.

Dor: A ferida cirúrgica não é espontaneamente dolorosa após 48 horas do ato cirúrgico. Quando o paciente se queixa de dor é judicioso acreditar nele. A dor é subjetiva e o seu limiar é imensurável. É importante um cuidadoso exame, antes de medicá-lo com analgésicos.

Cefaléia: É a mais freqüente complicação de uma raquianestesia. Excluídos outros fatores etiológicos, deve ser feita generosa reposição volêmica e endovenosa.

Pirose: Secundária ao refluxo gastroesofágico ácido ou alcalino, muito relacionada à presença de cateter nasogástrico nas primeiras horas de pós-operatório.

Soluço: Desagradável complicação cirúrgica determinada por irritação frênica, pequena quantidade de $\mathrm{CO} 2$ ou acidose respiratória.

Dispnéia: De imediato pensar na possibilidade de pneumopatia aguda ou no ínício de uma complicação cardíaca.

Febre: Evolução habitual da doença pós-operatória ou indício precoce de uma infecção aguda. Até 48 a 72 horas pode ser conseqüente apenas à reação à agressão cirúrgica.

Tosse: Exacerba a dor após laparotomia pode provocar evisceração e evidencia uma complicação do sistema respiratório.

Vômito: Habitual nas primeiras horas de pósoperatório. A realimentação oral precoce é uma importante causa de vômito. Antes da administração de um anti-emético, pensar na possibilidade de obstrução mecânica do tubo digestivo.

Oligúria: $O$ débito urinário na faixa de 30 a 50 $\mathrm{ml}$ por hora, com densidade satisfatória, constitui importante evidência de funções cardiovascular e renal satisfatórias.

Em resumo, a reavaliação sistemática do paciente cirúrgico permite o diagnóstico precoce e a intervenção rápida, passos fundamentais para o sucesso do tratamento das complicações pós-operatórias. 
Stracieri LDS. Care and complications post-surgical. Medicina (Ribeirão Preto) 2008; 41 (4): 465-8.

ABSTRACT: This study highlights the most important measures, concerning clinical conditions and post-anaesthetic recovery, which should be taken during the post-surgical period. The main factors within this context, including pain, possible infections, respiratory and cardiovascular complications, and other specific complications, are discussed.

keywords: Postoperative Period. Postoperative Complications. Postoperative Care.

\section{BIBLIOGRAFIA RECOMENDADA}

1 - Silva AL. Cirurgia de Urgência, Editora Medice, $2^{\underline{a}}$ ed., 1994.

2 - Petrez F, Pioner S. Pré e Pós-operatório, Editora Artmed, $2^{a}$ ed., 2003.

3 - Townsend e Sabiston. Tratado de Cirurgia, Editora Elsevier, $17^{\mathrm{a}}$ ed., 2005. Editora Elsvier.

4 - Moraes IN. Tratado de clinica cirurgica. In: Risco cirurgico e cuidados pré e pós-operatórios, 1르..., Rocca Editora, 2005.
5 - Brava Neto GP, Gonçalves MDC. Programa de auto-avaliação pré e pós-operatório. Rev. col. bras. cir. 1 (1): 1-35, 2001.

6 - Fischer JE. Mastery of surgery. Willianas \& Willians, Philadelphia, 5 st. Ed., 2007.

7 - Brunicard FC. Schwartz's principles of surgery. McGrawn USA, 8th. Ed., 2007.

Recebido para publicação em 20/08/2008

Aprovado para publicação em 23/10/2008 